\title{
Combining FAO-56 model and ground-based remote sensing to estimate water consumptions of wheat crops in a semi-arid region
}

\author{
S. Er-Raki ${ }^{a, *}$, A. Chehbouni ${ }^{a, b}$, N. Guemouria ${ }^{a}$, B. Duchemin ${ }^{a, b}$, J. Ezzahar $^{a}$, R. Hadria $^{a}$ \\ ${ }^{a}$ FSSM, Faculté des Sciences Semlalia Marrakech, Avenue Prince Moulay Abdellah, BP 2390, Marrakech 40000, Morocco \\ ${ }^{\mathrm{b}}$ CESBIO, Centre d'Etudes Spatiales de la Biosphère, 18 Avenue, Edouard Belin, bpi 2801, 31401 Toulouse Cedex 9, France
}

\section{A R T I C L E I N F O}

Article history:

Accepted 5 February 2006

Keywords:

Wheat

FAO-56

Evapotranspiration

Basal crop coefficient $\left(K_{\mathrm{cb}}\right)$

Normalized difference vegetation

index (NDVI)

Cover fraction $\left(f_{c}\right)$

\begin{abstract}
A B S T R A C T
This study was performed to test three methods based on the FAO-56 "dual" crop coefficient approach to estimate actual evapotranspiration (AET) for winter wheat under different irrigation treatments in the semi-arid region of Tensift $\mathrm{Al} \mathrm{Haouz,} \mathrm{Marrakech} \mathrm{(center} \mathrm{of}$ Morocco). The three methods differ in the calculation of the basal crop coefficient $\left(K_{\mathrm{cb}}\right)$ and the fraction of soil surface covered by vegetation $\left(f_{c}\right)$. The first approach strictly follows the FAO-56 procedure, with $K_{\mathrm{cb}}$ given in the FAO-56 tables and $f_{\mathrm{c}}$ calculated from $\mathrm{K}_{\mathrm{cb}}$ (NoCalibration method). The second method uses local $K_{\mathrm{cb}}$ and $f_{\mathrm{c}}$ values estimated from field measurements (Local-Calibration method) and the last approach uses a remotely-sensed vegetation index to estimate $K_{\mathrm{cb}}$ and $f_{\mathrm{c}}$ (NDVI-Calibration method). The analysis was performed on three fields using actual (AET) measured by Eddy Correlation systems. It was shown that the Local-Calibration approach gave best results. Accurate estimates of $K_{\mathrm{cb}}$ and $f_{\mathrm{c}}$ were necessary for FAO-56 "dual" crop coefficient application. The locally derived $K_{\mathrm{cb}}$ for winter wheat taken at initial, mid-season, and maturity crop growth were $0.15,0.90$ and 0.23 , respectively. The $K_{\mathrm{cb}}$ value at the mid-season stage was found to be considerably less than that suggested by the FAO-56.

Similarity between the seasonal pattern of normalized difference vegetation index (NDVI) and $K_{\mathrm{cb}}$ showed potential for modelling NDVI into a $K_{\mathrm{cb}}$. The obtained relationships between $K_{\mathrm{cb}}$ and NDVI, and between $f_{\mathrm{c}}$ and NDVI could be easily incorporated within the FAO-56 "dual" crop coefficient model and, thereby, provide a means to apply remotely sensed observation for real-time wheat irrigation scheduling.

The results obtained were very acceptable especially when the soil evaporation is negligible. Therefore, the $\mathrm{K}_{\mathrm{cb}}$-NDVI relationship employed in the FAO-56 "dual" crop coefficient model holds great potential for estimating crop water requirements on an operational basis and consumption at a regional scale.
\end{abstract}

(C) 2006 Elsevier B.V. All rights reserved.

\section{Introduction}

Within the arid and semi-arid regions, water availability is a major limitation for crop production. The Haouz plain that surrounds the city of Marrakech (Center of Morocco) is classified among regions with scarce water resources (Pascon, 1977). In recent years, due to the combined effect of drought and the increase of irrigated surfaces, water storage has

* Corresponding author at: Projet SudMed, Centre Geber salle 26, Faculty of Science Semlalia, Université Cadi Ayyad BP 2390, Marrakech, Morocco. Tel.: +212 444316 26; fax: +212 44431626 .

E-mail address: s.erraki@ucam.ac.ma (S. Er-Raki).

0378-3774/\$ - see front matter (C) 2006 Elsevier B.V. All rights reserved.

doi:10.1016/j.agwat.2006.02.004 
gradually decreased in this region. The dam that provides water for irrigation is at about $50 \%$ of its capacity and the ground water level decreases by about $1 \mathrm{~m}$ every year. Consequently, agriculture in this region might be in jeopardy if no sustainable water management is implemented.

A better understanding of the water balance is essential for exploring water-saving techniques. One of the most important concepts regarding water balance in semi-arid areas is crop evapotranspiration (ET) which is a key factor for determining proper irrigation scheduling and for improving water use efficiency in irrigated agriculture. Accurate estimation of evapotranspiration constitutes a very important part of irrigation system planning and designing, and accurate spatial determination is crucial to achieving sustainable agriculture.

In Morocco, cereals covered $59 \%$ of ploughed areas during the 1990-2000 decade (Karrou, 2003). Therefore, the monitoring of cereal water needs and consumption is a major challenge for developing a regionally sustainable irrigation strategy. In this regard, the SudMed project (Chehbouni et al., 2003) focuses on integrated water management at the Tensift river basin which include the Haouz plain. In this region, the evaporative demand - around $1600 \mathrm{~mm}$ /year according to reference evapotranspiration estimates (Allen et al., 1998) - is very large when compared with rainfall, which is about $240 \mathrm{~mm}$ /year.

Substantial advances have been made over the last two decades in improving the understanding of the factors that control ET in water limited zones and consequently a large number of new techniques and methodologies are available for use in irrigation management and/or irrigation Scheduling: when to irrigate the crops and how much water to apply. However, a fundamental requirement for accurate irrigation scheduling is to determine actual crop evapotranspiration (AET) for each day during the growing season. Existing, methods range from simple empirical approaches to more sophisticated, physically based ones. However, for operational purposes, the FAO-56 model is often preferred because it only requires phenological data and standard meteorological parameters while resulting in acceptable AET estimates compared to data and parameter hungry physically-based models (Evett et al., 1995; Kite and Droogers, 2000; Allen, 2000; Eitzinger et al., 2002). The FAO-56 approach is based on the concepts of combining reference evapotranspiration $\mathrm{ET}_{0}$ and crop coefficients $\left(K_{c}\right)$. There are two methods used to estimate crop evapotranspiration: the single and the dual crop coefficients. In the single crop coefficient $\left(K_{c}\right)$, the effect of crop transpiration and soil evaporation are combined into a single $K_{\mathrm{c}}$. The dual crop coefficient consists of two coefficients: a basal crop coefficient $\left(K_{\mathrm{cb}}\right)$ and a soil evaporation coefficient $\left(K_{\mathrm{e}}\right)$. This latter approach is mainly used in research and real-time irrigation scheduling for high frequent water applications (Allen et al., 1998). There are several reports on the estimation of crop coefficients $K_{c}$ for many crops (e.g. Doorenbos and Pruitt, 1977; Doorenbos and Kassam, 1979; Pruitt et al., 1987; Snyder et al., 1987; Jensen et al., 1990; Allen et al., 1998). However, there is no simple way to calculate those crop coefficients, as these coefficients are function of climate, soil type, the particular crop and its varieties, irrigation method, soil water, nutrient content and plant phenology (Allen et al., 1998). Consequently, specific adjustment of crop coefficients in various climatic regions is necessary. Unfortunately, values of $K_{c}$ for winter wheat growing in the Tensift river basin are not currently available.

It has been shown that remotely sensed spectral reflectance may provide an indirect estimate for crop coefficient $K_{\mathrm{c}}$ (e.g. Bausch, 1993; Gutman, 1999; Bastiaanssen et al., 2000). Estimating $K_{\mathrm{c}}$ from spectral measurements is possible because $K_{c}$ and vegetation indices are both sensitive to leaf area index and fractional ground cover (Heilman et al., 1982; Neale et al., 1989; Jackson and Huete, 1992; Choudhury et al., 1994; Moran et al., 1995). Several studies have been specifically dedicated for estimating $K_{\mathrm{c}}$ from vegetation indices (VI) (e.g. Normalized Difference Vegetation Index NDVI (Rouse et al., 1974), Soil Adjusted Vegetation Index (SAVI) (Huete, 1988)). Jackson et al. (1980) showed a similarity of the seasonal pattern of $K_{\mathrm{c}}$ and (VI) for the wheat. Bausch and Neale (1987) and Neale et al. (1989) established relationships between $K_{\mathrm{cb}}$ and different vegetation index for the corn in the Colorado. As reported in Hunsaker et al. (2003), Bausch and Neale (1989), Bausch $(1993,1995)$ futher investigated those relationships and developed some algorithms for irrigation scheduling and for good estimating water use of the corn. Allen and Tasumi (2003), Er-Raki et al. (2004) and Duchemin et al. (2006) found that the relationship between $K_{c}$ and NDVI for winter wheat is affected by soil evaporation. Hunsaker et al. (2003) obtained two regression relations between basal crop coefficient $K_{\mathrm{cb}}$ and NDVI for cotton grown in the Southwestern USA: a linear function of $K_{\mathrm{cb}}$ versus NDVI is used to estimate $K_{\mathrm{cb}}$ from early vegetative growth to effective full cover, and a multiple regression of $K_{\mathrm{cb}}$ as a function of NDVI and cumulative growing degree day (CGDD) is used to estimate $K_{\mathrm{cb}}$ after effective full cover is attained. Recently, Duchemin et al. (2006) found a linear relationship between $K_{\mathrm{cb}}$ and NDVI with a good accuracy (15\%) for winter wheat grown in semi-arid region in central Morocco. As a first application of this relationship in multispectral satellite imagery, $9 \mathrm{~km} \times 9 \mathrm{~km}$ maps of transpiration requirements $\left(K_{\mathrm{cb}} \cdot \mathrm{ET}_{0}\right)$ was processed from two Landsat7-ETM+ images acquired on the 23rd of January and 31st of March, 2003. The maps provide with an indication on how the water should be distributed spatially and temporally in order to improve the efficiency of irrigation (Duchemin et al., 2006).

In the present study, we applied the FAO-56 "dual" crop coefficient model to estimate seasonal AET over winter wheat under different irrigation treatments in the semi-arid region of Tensift Al Haouz, Marrakech (center of Morocco). The specific objectives of the study were:

1. To assess the capability of FAO-56 "dual" crop coefficient model for providing accurate estimates AET over winter wheat at three contrasted fields using standard $K_{\mathrm{cb}}$ values.

2. As the first objective except using locally calibrated values of $K_{\mathrm{cb}}$.

3. To investigate the possibility of deriving $K_{\mathrm{cb}}$ from NDVI and to assess the stability of the relationship from field to field.

4. To compare the performances of three methods (above) based on the FAO-56 "dual" crop coefficient approach, 
which differ in the estimation of $K_{\mathrm{cb}}$ and the fraction of soil surface covered by vegetation $f_{\mathrm{c}}$.

This paper is organized as follows. In Section 2, we provide a theoretical background of the FAO-56 "dual" crop coefficient approach. In Section 3, we provide a description of study sites and data collected during 2002-2003 season. Section 4 presents the adaptations of the FAO-56 "dual" crop coefficient model. Section 5 presents the results obtained by three methods (NoCalibration, Local-Calibration and NDVI-Calibration), compares their performances, and concludes by discussing the advantage and the limitation associated with each method.

\section{Theoretical background of the FAO-56 "dual" crop coefficient approach}

The theoretical basis of the FAO-56 model has been discussed in many papers. In this section, we will breifly present the FAO-56 "dual" crop coefficient approach. For more details, the reader can refer to a comprehensive review by Allen et al. (1998). The FAO-56 "dual" approach has been extensively used to derive crop evapotranspiration and for irrigation scheduling on an operational basis. It is based on the concepts of reference evapotranspiration $E T_{0}$ and crop coefficients $K_{C}$, which have been introduced to separate the climatic demand from the plant response $\mathrm{ET}_{\mathrm{C}}$ (Allen et al., 1998):

$E T_{\mathrm{c}}=\left(\mathrm{K}_{\mathrm{cb}}+\mathrm{K}_{\mathrm{e}}\right) * E \mathrm{~T}_{0}$,

where $K_{\mathrm{e}}$ represents the component of soil evaporation, $K_{\mathrm{cb}}$ is the basal crop coefficient (plant transpiration), which represents the ratio of $E T_{\mathrm{C}}$ to $E \mathrm{~T}_{0}$ under a well watered condition with no stress and no soil evaporation. For actual estimates of actual crop evapotranspiration (AET), $K_{\mathrm{cb}}$ is adjusted by the water stress coefficient $K_{\mathrm{s}}$ :

$\mathrm{AET}=\left(\mathrm{K}_{\mathrm{cb}} \mathrm{K}_{\mathrm{s}}+\mathrm{K}_{\mathrm{e}}\right) \mathrm{ET}_{0}$,

where $K_{\mathrm{s}}<1$ for conditions where the soil water is a limiting factor, and $K_{\mathrm{s}}=1$ when there is no shortage of water. Consequently, three parameters are necessary to determine (AET): $K_{\mathrm{cb}}, K_{\mathrm{e}}$ and $\mathrm{K}_{\mathrm{s}}$.

\subsection{Calculation of $\mathrm{K}_{\mathrm{cb}}$}

In the FAO-56 "dual" procedures, the $K_{\mathrm{cb}}$ curve is divided into four growth stage periods: the initial $\left(l_{\text {ini }}\right)$, the development $\left(l_{\text {dev }}\right)$, the mid-season $\left(l_{\text {mid }}\right)$ and the late season $\left(l_{\text {late }}\right)$. The initial and mid-season periods are characterized by horizontal line segments and the development and late season periods are characterized by rising and falling line segments respectively. Three point values for $K_{\mathrm{cb}}$ are required to generate the $K_{\mathrm{cb}}$ curve, namely the $K_{\mathrm{cb}}$ during the initial period, $K_{\mathrm{cbini}}$, the $K_{\mathrm{cb}}$ during the mid-season, $K_{\mathrm{cbmid}}$, and the $K_{\mathrm{cb}}$ at the end of the growth season, $K_{\text {cbend. }}$.

The lengths of growth stages $\left(l_{\text {ini }}, l_{\mathrm{dev}}, l_{\text {mid }}, l_{\text {late }}\right)$ were computed according the FAO-56 method as a fraction of vegetation cover $f_{c}$. The initial stage $\left(l_{\text {ini }}\right)$ runs from sowing date to when $f_{c}$ reach a value of 0.1 , the development stage $\left(l_{\mathrm{dev}}\right)$ runs from $f_{\mathrm{c}}$ of 0.1 to full vegetation cover $\left(f_{\mathrm{c}}\right.$ of 0.9$)$, the mid-season stage $\left(l_{\mathrm{mid}}\right)$ runs from the end of development stage until canopy cover $f_{c}$ drops back to the same value it had at the end of the development stage and the beginning of the mid-season period $\left(f_{c}=0.9\right)$. The late season stage (l late runs from end of the mid-season stage until the end of growing season. When $f_{c}$ does not reach 1 , the mid-season stage can be assumed to have started when $f_{c}$ became equal to $90 \%$ of maximum $f_{c}$ value reached.

\subsection{Calculation of $\mathrm{K}_{e}$}

In general, the soil evaporation coefficient, $K_{e}$ reaches a maximal value after rainfall or irrigations events and fall to zero when the soil surface is dry and thus no evaporation occurs. Its evalution requires a daily water balance computation for the surface soil evaporation layer of effective depth $Z_{\mathrm{e}}$. The calculation procedure necessitates input of soil parameters such as soil moisture at field capacity $\left(\theta_{\mathrm{fc}}\right)$ and at the wilting point $\left(\theta_{\mathrm{wp}}\right)$, the evaporable water REW, and the depth of $Z_{\mathrm{e}}$ (see Section 4 for the calculation of these parameters).

\subsection{Derivation of $\mathrm{K}_{\mathrm{s}}$}

Similarly to $K_{e}$, the estimation of $K_{\mathrm{s}}$ requires a daily balance computation for the root zone, $Z_{\mathrm{r}}$. Mean water content at the root zone is expressed through the root zone depletion, $D_{\mathrm{r}}$. At the field capacity, the root zone depletion is zero $\left(D_{r}=0\right)$ and $K_{\mathrm{s}}=1$ (no stress). Water stress occurs when $D_{\mathrm{r}}$ becomes superior to RAW, the depth of readily available water in the root zone. For $D_{r}>$ RAW, $K_{s}$ is given by (Allen et al., 1998):

$K_{\mathrm{s}}=\frac{\mathrm{TAW}-\mathrm{D}_{r}}{\mathrm{TAW}-\mathrm{RAW}}=\frac{\mathrm{TAW}-\mathrm{D}_{r}}{(1-p) \mathrm{TAW}}$

where TAW is the total available soil water at the root zone [mm], and $p$ is the fraction of TAW that a crop can extract from the root zone under no water stress conditions. When $D_{\mathrm{r}} \leq$ RAW $K_{\mathrm{s}}=1$.

TAW is derived from the daily crop rooting depth $\left(Z_{\mathrm{r}}\right)$ and the $\theta_{\mathrm{fc}}$ and $\theta_{\mathrm{wp}}$ for soil at the rooting depth:

$\mathrm{TAW}=1000\left(\theta_{\mathrm{fc}}-\theta_{\mathrm{wp}}\right) \mathrm{Z}_{\mathrm{r}}$

RAW is estimated as:

RAW $=p$ TAW

The recommended $p$ value is 0.55 for winter wheat when $E T_{\mathrm{C}}$ is $5 \mathrm{~mm}$ day $^{-1}$ (FAO-56, Table 22). When $\mathrm{ET}_{\mathrm{C}}$ differed from $5 \mathrm{~mm} \mathrm{day}^{-1}, p$ can be adjusted using the following approximation:

$p=0.55+0.04\left(5-E T_{c}\right)$

\section{Experimental data}

\subsection{Region of interest}

The experimental site is located in the Haouz plain semi-arid region in the centre of Morocco, $40 \mathrm{~km}$ East of Marrakesh city $\left(31^{\circ} 68^{\prime} \mathrm{N}, 7^{\circ} 38^{\prime} \mathrm{W}, 550 \mathrm{~m}\right.$ above mean sea level) (Fig. 1). It is an irrigated area managed by the ORMVAH (Office Régional de 


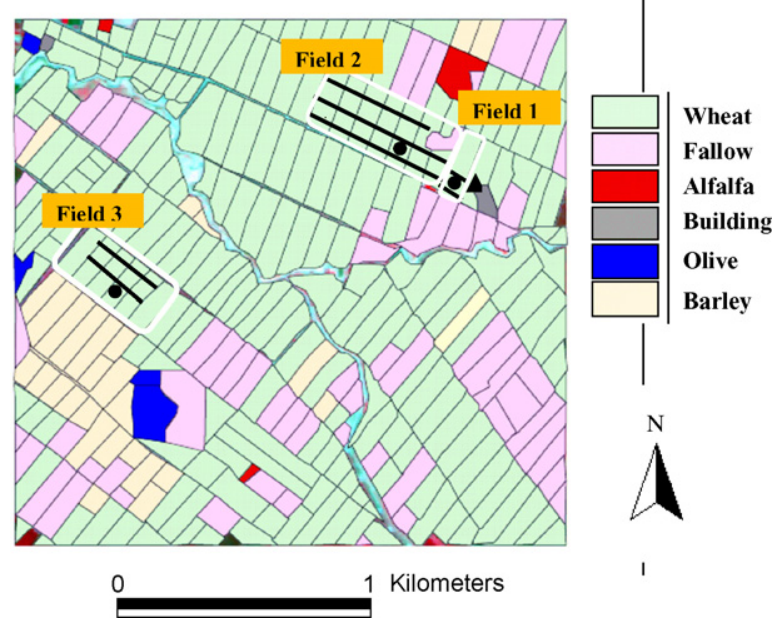

Fig. 1 - Land cover (coloured shapes) and location of three wheat fields (delimited with white rectangles) under study during 2002-2003 agricultural season in the Tensift AL Haouz, Marrakech, Morocco. The surrounding irrigation units are highlighted (black rectangles). The meteorological station (black triangle) and the towers equipped with evapotranspiration measurement systems (black disks) are located. The surface reflectances were measured with MSR87 sensor (hand-held radiometer) along transects (bold solid lines) every $10 \mathrm{~m}$. (For interpretation of the references to colour in this figure legend, the reader is referred to the web version of the article.)

Mise en Valeur Agricole du Haouz) since the year 1999. The area covers 2800 ha and is almost flat. The dominant crops are cereals, more wheat than barley (see Fig. 1). The wheat is generally sown between mid November and mid January, depending on climatic conditions and the start of the rainfall season.

The climate in the area is typically Mediterranean semiarid, with around $250 \mathrm{~mm}$ of average annual rainfall, concentrated mainly from autumn to spring, and an average annual $\mathrm{ET}_{0}$ of $1600 \mathrm{~mm}$. The soil is very homogeneous; it is poor in organic matter $(<2 \%)$, with a fine texture (clay to loamy).

In this irrigated area, ORMVAH manages the distribution of water starting from December through May. The frequency and the amount of water for each irrigation are predetermined depending on the dam water level at the beginning of the cropping season without any consideration of the actual soil moisture status. Additionally flood irrigation is the most widely used method in this district.

\subsection{Field experiments}

Three wheat fields (denoted 1, 2 and 3 in Fig. 1) were fully equipped with instrument measurements described below (see Duchemin et al. (2006) and Hadria et al. (2005) for full details). All fields were cropped with durum variety wheat (Karim), which has relatively short life cycle. This variety is suitable for semi-arid conditions and commonly used in the Marrakech-Haouz plain (ORMVAH technical documentation, Karrou, 2003).

The studied fields were irrigated by using concrete canals that carry water from the main canal to the irrigated units, which include six fields of 4 ha each (see Fig. 1). Table 1 summarizes the sowing and the irrigation dates of the three studied fields. Each field is periodically irrigated by flooding with a mean $30 \mathrm{~mm}$ of water regardless of the precipitation and thus soil moisture condition. Fertilizers were applied only in field 1 at the rate of $100 \mathrm{~kg} / \mathrm{ha}$ of NPK (14-28-14) at the beginning of grain filling phase. Fertilization depends on the economical capability of the owner and the experience of the manager.

\subsection{Data description}

From December 2002 to May 2003, the experiment was carried out on wheat crops to monitor the variables of the surface energy and water balance as well as soil and vegetation data during the entire growing cycle:

\subsubsection{Latent heat fluxes and meteorological data}

Three eddy covariance (EC) systems were installed over each field to measure the latent heat and sensible heat fluxes (black disks in Fig. 1). The eddy covariance system consists of commercially available instrumentation: a 3D sonic anemometer (CSAT3, Campbell Scientific Ltd.) which measured the fluctuations in the wind velocity components and temperature; and an open-path infrared gas analyzer (Li7500, Licor Inc.) which measured concentration of water vapour and carbon dioxide. Raw data were sampled at a rate of $20 \mathrm{~Hz}$ and were recorded using CR23X data loggers (Campbell Scientific Ltd.). A detailed description of (EC) measurements in each field can be found in Duchemin et al. (2006). 44 (between DAS 69 and

Table 1 - Sowing and irrigations dates for three fields of study

\begin{tabular}{llll}
\hline Sowing and irrigation dates & \multicolumn{1}{c}{ Field 1 } & \multicolumn{1}{c}{ Field 2 } & Field 3 \\
\hline Sowing date & 11 January & 14 January & 17 December \\
First irrigation & 1 February (DAS ${ }^{\mathrm{a}}$ 22) & 4 February (DAS 22) & 28 January (DAS 43) \\
Second irrigation & 21 February (DAS 42) & 20 March (DAS 66) & 22 February (DAS 68) \\
Third irrigation & 14 March (DAS 63) & 13 April (DAS 90) & 10 April (DAS 115) \\
Fourth irrigation & 24 March (DAS 73) & 21 April (DAS 98) & \\
Fifth irrigation & 7 April (DAS 87) & \\
Sixth irrigation & 24 April (DAS 111) & & \\
\hline \multicolumn{2}{c}{ a DAS means day after sowing. } & &
\end{tabular}


118), 71 (between DAS 23 and 127) and 55 (between DAS 91 and 155) data sets of AET measurements have been available for fields 1, 2 and 3, respectively. Missing data in some days is due to problems with the power supply. The approximate fetch (spatial scale) of (AET) measurement is between $100 \mathrm{~m}^{2}$ to few hectares (Duchemin et al., 2006), depending on wind speed.

In addition to sensible and latent heat fluxes measurements, 30 min measurements of classical climatic data were collected over a site very close to the fields 1 and 2 (blank triangle in Fig. 1). A 6-m tower was equipped to measure air temperature and relative humidity using HMP45C, Vaisala; wind speed and direction using an anemometer (A100R anemometer, R.M. Young Company, USA); incoming solar radiation using Kipp \& Zonen radiometer (CNR1, Kipp \& Zonen, Netherlands), and finally the rainfall using an automatic rain gauge station (FSS500 tipping bucket automatic rain gauge, Campbell Inc., USA).

Additionally, Time Domain Reflectometry (TDR) probes (model CS615; Campbell Scientific, Inc.) have been installed in a soil pit near the fluxes measurement tower to measure soil water content at different soil depths.

\subsubsection{Normalized difference vegetation index (NDVI)}

On a weekly basis, measurements of canopy reflectances were made using hand-held radiometer (MSR87 MultiSpectral Radiometer, Cropscan Inc., USA) with eight spectral bands. Fifteen sets of canopy reflectance measurements were made between January 8 and May 27 for the fields 1 and 2, and 12 sets of measurements were made between January 16 and May 20 in field 3. Each measurement was taken with the MSR87 sensor $3 \mathrm{~m}$ high in a vertical position along several transects every $10 \mathrm{~m}$ (see Fig. 1). The field-of-view was $28^{\circ}$ and the instrument sampled an elementary area of around $2 \mathrm{~m}^{2}$ each time. Wood markers were installed in the fields to allow the observations to be made at the same place each time (bold solid lines in Fig. 1). The average values of NDVI were computed, field by field, from the elementary measurements.

Reflectance values centred on red ( $\left.\rho_{\text {red }}, 0.63-0.69 \mu \mathrm{m}\right)$ and near infrared $\left(\rho_{\text {PIR }}, 0.76-0.90 \mu \mathrm{m}\right.$ ) bands are used to obtain the normalized difference vegetation index values NDVI (Rouse et al., 1974):

$$
\mathrm{NDVI}=\frac{\rho_{\text {PIR }}-\rho_{\text {red }}}{\rho_{\text {PIR }}+\rho_{\text {red }}}
$$

It worth to mention that this radiometer has been successfully inter-calibrated with ASD (Analytical Spectral Device) before the start of the growing season of 2002-2003.

\subsubsection{Fraction of soil surface covered by vegetation $f_{c}$}

A hemispherical canopy photo apparatus equipped with a fisheye lens with a field-of-view of $183^{\circ}$ (Nikon Coolpix $950^{\circledR}$ with a FC-E8 fish-eye lens converter) was used to obtain $f_{c}$. This technique has been widely used on forests to provide information on position, size, density, and distribution of canopy gaps (e.g. Van Gardingen et al., 1999; Englund et al., 2000; Sibernagel and Moeur, 2001; Hale and Edwards, 2002; Jonckheere et al., 2003). It was adapted here by taking photos above wheat canopy and using colour threshold to separate the soil from vegetation. The threshold was constant and applied on a green index computed as the ratio of the difference to the sum of the red and the green bands. This allowed obtaining binary soil/vegetation images from which the fraction of surface covered by vegetation is derived as the percentage detected as vegetation considering a view zenith angle lower than $7^{\circ}$ (practically nadir).

\section{Adaptation of the FAO-56 "dual" crop coefficient procedure}

The FAO-56 "dual" crop coefficient approach was provided in Section 2; refer to Allen et al. (1998) for full details.

The FAO-56 "dual" crop coefficient approach is driven by meteorological forcing parameters, such as air temperature, air humidity, wind speed and solar radiation to calculate reference evapotranspiration $\mathrm{ET}_{0}$.

The reference evapotranspiration, $\mathrm{ET}_{0}$, was calculated according to the FAO Penman-Monteith equation (Allen et al., 1998). For daily calculation time steps, the equation is:

$\mathrm{ET}_{0}=\frac{0.408 \Delta\left(R_{n}-G\right)+\gamma \frac{900}{\mathrm{~T}+273} u_{2}\left(e_{\mathrm{s}}-e_{\mathrm{a}}\right)}{\Delta+\gamma\left(1+0.34 u_{2}\right)}$

where $\mathrm{ET}_{0}$ expressed in $\left(\mathrm{mm} \mathrm{day}^{-1}\right) ; \mathrm{R}_{n}$ net radiation at the crop surface (MJ/m² day); $G$ soil heat flux density $\left(\mathrm{MJ} / \mathrm{m}^{2}\right.$ day); $\mathrm{T}$ air temperature at $2 \mathrm{~m}$ height $\left({ }^{\circ} \mathrm{C}\right) ; \mathrm{u}_{2}$ wind speed at $2 \mathrm{~m}$ height $(\mathrm{m} / \mathrm{s}) ; e_{\mathrm{s}}$ saturation vapour pressure $(\mathrm{kPa}) ; e_{\mathrm{a}}$ actual vapour pressure; $\Delta$ the slope of the vapour pressure curve $\left(\mathrm{kPa} /{ }^{\circ} \mathrm{C}\right)$ and $\gamma$ is the psychrometric constant $\left(\mathrm{kPa} /{ }^{\circ} \mathrm{C}\right)$.

In applications with 24-h time steps, $G$ is assumed to be $0 \mathrm{MJ} / \mathrm{m}^{2}$ day and $e_{\mathrm{s}}$ is computed as: $e_{\mathrm{s}}=\frac{e^{0}\left(T_{\max }\right)+e^{0}\left(T_{\min }\right)}{2}$, where $e^{0}()$ is the saturation vapour function and $T_{\max }$ and $T_{\min }$ are the daily maximum and minimum air temperature, respectively.

The FAO Penman-Monteith equation predicts the evapotranspiration from a hypothetical grass reference surface that is $0.12 \mathrm{~m}$ in height with a surface resistance of $70 \mathrm{~s} \mathrm{~m}^{-1}$ and an albedo of 0.23 . The equation provides a standard for comparing evapotranspiration during various periods of the year, in different regions, and for different crops. Standardised equations for computing all parameters in Eq. (5) are given in (Allen et al., 1994a,b, 1998) or (Smith et al., 1991).

Fig. 2 shows the seasonal variations of the reference evapotranspiration $\mathrm{ET}_{0}$ of well-watered grass calculated by Eq. (1) for the meteorological forcing parameters collected over our study site. The $\mathrm{ET}_{0}$ pattern is characteristic of semi-arid continental climates. The mean value of $\mathrm{ET}_{0}$ during the growing season (between January and May) is $3.6 \mathrm{~mm} \mathrm{day}^{-1}$. Precipitation patterns over the 2002-2003 growing season were characterized by low and irregular rainfall events, for which the cumulative precipitation was about $200 \mathrm{~mm}$ between January and May 2003.

Additional surface characteristics (see below), including soil texture (\% clay, \% sand and \% loam), root depth $Z_{\mathrm{r}}, Z_{\mathrm{e}}$, and vegetation parameters such as $K_{\mathrm{cb}}$ at three different stages of growth, $f_{\mathrm{c}}$ and the vegetation height $(h)$ are also needed.

\subsection{Soil parameters}

Soil parameters required to determine daily $K_{e}$ include the soil moisture at field capacity $\left(\theta_{\mathrm{fc}}\right)$ and wilting point $\left(\theta_{\mathrm{wp}}\right)$, the 


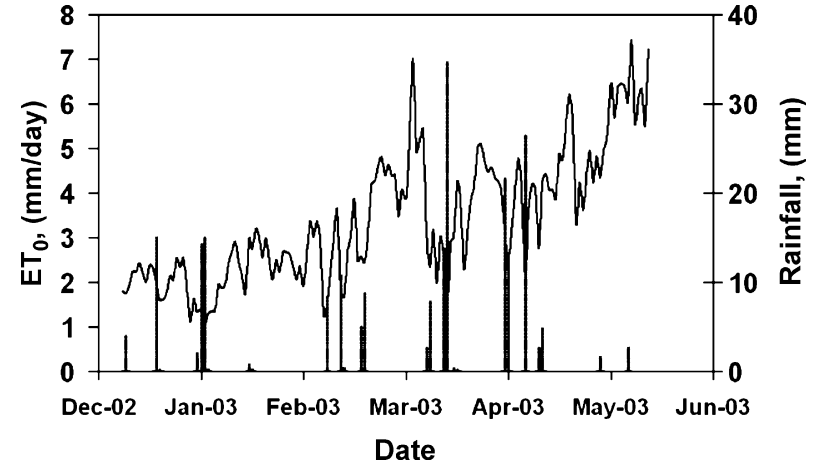

Fig. 2 - Daily reference evapotranspiration $\mathrm{ET}_{0}$ calculated following the FAO-Penman-Monteith equation (Allen et al., 1998) during 2002-2003 agricultural season. Rainfall events are shown in the same figure.

readily evaporable water $\mathrm{REW}$, and the depth of $Z_{\mathrm{e}}$. For the site soil texture ( $47 \%$ of clay, $33 \%$ of loam and $18.5 \%$ of sandy), Allen et al. (1998) indicates that the value of the soil moisture at field capacity $\left(\theta_{\mathrm{fc}}\right)$ is between 0.3 and $0.37 \mathrm{~m}^{3} \mathrm{~m}^{-3}$ and the soil moisture at wilting point $\left(\theta_{\mathrm{wp}}\right)$ is between 0.17 and $0.24 \mathrm{~m}^{3} \mathrm{~m}^{-3}$. Wosten (1997) and Wosten et al. (1999) suggests the pedotransfer functions to estimate the field capacity and wilting point as a function of soil texture using the model proposed by Van Genutchen (1980). The values of $\theta_{\mathrm{fc}}$ obtained by the model of Wosten (1997) and Wosten et al. (1999) were respectively 0.33 and $0.32 \mathrm{~m}^{3} \mathrm{~m}^{-3}$, for $\theta_{\mathrm{wp}}$ the values of 0.20 and $0.17 \mathrm{~m}^{3} \mathrm{~m}^{-3}$ were obtained respectively by both models. We see that the values of $\theta_{\mathrm{fc}}$ and $\theta_{\mathrm{wp}}$ obtained by both models are in the range given by Allen et al. (1998), but the value of $\theta_{\mathrm{wp}}$ given by Wosten (1997) was found to be inconsistent with the minimum observed water content in the root zone. Based on these considerations, the Wosten et al. (1999) model was adopted for our type of soil: an average value of $0.32 \mathrm{~m}^{3} \mathrm{~m}^{-3}$ for $\theta_{\mathrm{fc}}$ and of $0.17 \mathrm{~m}^{3} \mathrm{~m}^{-3}$ for $\theta_{\mathrm{wp}}$ was adopted in this study. For the depth of soil surface evaporation layer $Z_{e}(m)$, Allen et al. (1998) suggests that the value was between 0.10 and $0.15 \mathrm{~mm}$. The value of $Z_{e}=0.1 \mathrm{~m}$ is used in the calculations. A typical REW value for a silt clay loam soil of $9 \mathrm{~mm}$ (FAO-56, Table 19) was used in the calculations.

\subsection{Plant parameters}

The main plant parameters needed to run the FAO-56 dual crop coefficient model are: the lengths of growing stages $\left(l_{\text {ini }}\right.$, $\left.l_{\text {dev }}, l_{\text {mid }}, l_{\text {late }}\right)$, the values of basal crop coefficient $\left(K_{\text {cbini }}\right.$, $K_{\text {cbmid }}$ and $K_{\text {cbend }}$ ) at three crop growth stages (initial, midseason and maturity respectively), $f_{c}$, the height of vegetation and the rooting depth $Z_{\mathrm{r}}$. In our study, it was assumed that $Z_{\mathrm{r}}$ varies between a minimum value (maintained during the initial crop growth stage) and a maximum value (reached at the beginning of the mid-season stage). The minimum rooting depth is the effective rooting depth during the initial stage from which the germinating seed can extract water. A minimum rooting depth of $0.1 \mathrm{~m}$ is considered. The maximum rooting depth was measured and found equal to 0.5 , 0.52 and $0.55 \mathrm{~m}$ for fields 1,2 and 3, respectively. The height of vegetation was measured weekly using the graduated ruler. Other vegetation parameters $\left(l_{\text {ini }}, l_{\text {dev }}, l_{\text {mid }}, l_{\text {late }}, K_{\text {cbini }}\right.$, $K_{\text {cbmid }}, K_{\text {sbend }}$ and $f_{c}$ ) were determined according to the method used.

As described previously, our approach consisted of using three methods based on FAO-56 "dual" crop coefficient which only differ in the method used to estimate $K_{\mathrm{cb}}$ and $f_{\mathrm{c}}$. In the first "No-Calibration" method, we used $K_{\mathrm{cb}}$ given in FAO-56 tables, and $f_{\mathrm{c}}$ calculated from $K_{\mathrm{cb}}$. In the second "Local-Calibration" approach, these parameters are locally derived from field observations. The third method "NDVICalibration" consists of establishing relationships between $K_{\mathrm{cb}}$ and $f_{\mathrm{c}}$ and ground based measurements of NDVI. The derived relationships between $K_{\mathrm{cb}}$ and NDVI, and between $f_{\mathrm{c}}$ and NDVI are described in the following paragraph.

\section{3. $\mathrm{K}_{\mathrm{cb}}-\mathrm{NDVI}$ and $f_{\mathrm{c}}-\mathrm{NDVI}$ relationships}

A relationship between $K_{\mathrm{cb}}$ and NDVI can be established under conditions when, first, the soil surface layer is dry and, second, the soil water within the root zone is adequate to sustain full plant transpiration (non-stressed conditions). In this context, an exponential function between (NDVI) and leaf area index (LAI) has been established by Duchemin et al. (2006):

$\mathrm{NDVI}=\mathrm{NDVI}_{\max }-\left(\mathrm{NDVI}_{\max }-\mathrm{NDVI}_{\min }\right) \exp (-0.54 \mathrm{LAI})$

where $\mathrm{NDVI}_{\text {min }}$ and $\mathrm{NDVI}_{\text {max }}$ are the minimum and the maximum values of NDVI associated with bare soil and dense vegetation, respectively. The values 0.14 and 0.93 are used here. Similarly, an exponential relationship between $K_{\mathrm{cb}}$ and LAI has been established (Duchemin et al., 2006):

$K_{\mathrm{cb}}=1.07(1-\exp (-0.84 \mathrm{LAI}))$

Eqs. (6) and (7) can be combined by eliminating LAI to obtain the following relationship between $K_{\mathrm{cb}}$ and NDVI:

$K_{\mathrm{cb}}=1.07\left[1-\left(\frac{\mathrm{NDVI}_{\max }-\mathrm{NDVI}}{\mathrm{NDVI}_{\max }-\mathrm{NDVI}_{\min }}\right)^{0.84 / 0.54}\right]$

Derived $f_{c}$ from hemispheric photos were approximated by a linear function of NDVI as illustrated in Fig. 3:

$f_{\mathrm{c}}=1.18\left(\mathrm{NDVI}-\mathrm{NDVI}_{\min }\right)$

Plotting the values of $f_{c}$ estimated from this last equation against the ones derived from hemispheric photos (data not presented here) revealed a quasi-perfect agreement. The values of root mean square error (RMSE), the efficiency ( $E$ ) and the mean bias error (MBE) were respectively $0.10,0.88$ and 0.03 .

\section{Results and discussions}

Before discussing the performance of each method for estimating wheat evapotranspiration, the difference between parameters used by each method are explicitly reported. Table 2 summarized the parameters used to calculate AET using the FAO-56 "dual" crop coefficient model for three methods mentioned above. The main differences 


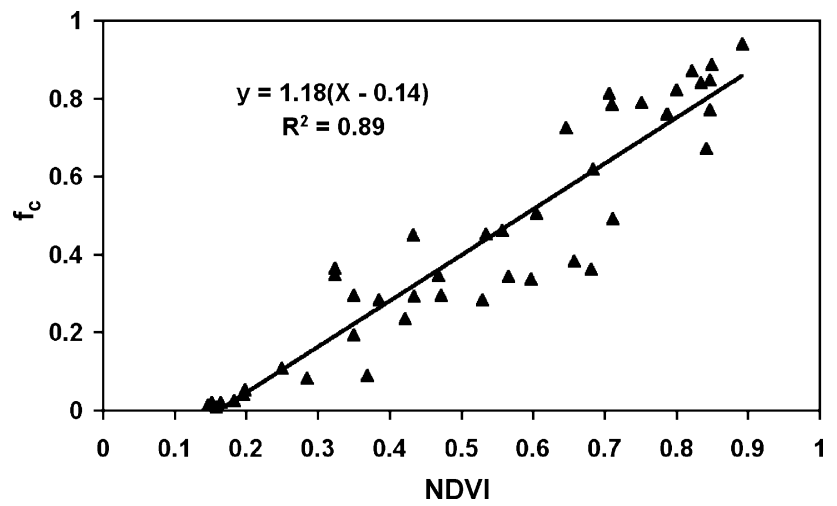

Fig. $3-f_{\mathrm{c}}-\mathrm{NDVI}$ relationship. The values of $f_{\mathrm{c}}$ are derived from hemispherical photos taking at nadir of the crop. NDVI are derived from spectral reflectance measurements using the hand-held MSR87 radiometer.

among the three methods are the approach used to derive $K_{\mathrm{cb}}$ and $f_{\mathrm{c}}$. The values of basal crop coefficient $\left(K_{\mathrm{cbini}}\right.$, $\mathrm{K}_{\mathrm{cbmid}}$ and $\mathrm{K}_{\text {cbend }}$ ) at three crop growth stages used by NoCalibration method were taken from Table 17 in Allen et al. (1998) and $f_{c}$ was estimated as a function of basal crop coefficient (Eq. (76) in Allen et al., 1998). Local-Calibration method used a locally derived basal crop coefficient $K_{\mathrm{cb}}$ and $f_{\mathrm{c}}$ based on field measurements. NDVI-Calibration method used $K_{\mathrm{cb}}$ and $f_{\mathrm{c}}$ derived from ground measured NDVI. As shown in Table 2 the total length of growth stages (initial, mid-season and maturity) derived locally were found to be shorter to those provided in Table 11-FAO-56 (Allen et al., 1998). This is due to the fact that the fields were cropped with a short duration wheat variety which is more adapted to the semi-arid conditions of the Haouz plain. The length of crop development stages vary from field to field. This is due to the difference of the date of sowing among the three fields.

Figs. 4 and 5 respectively show the time course of $f_{c}$ and $K_{\mathrm{cb}}$ used by different methods and for three fields. The derived green cover from hemispheric photograph (LocalCalibration) or from NDVI (NDVI-Calibration) was also plotted in Fig. 4. During the initial stage, the values of $f_{\mathrm{c}}$ estimated by No-Calibration method were equal to 0 for all fields, this is can be expected since the $K_{\mathrm{cb}}$ at this stage has the same value than the minimum crop coefficient used for annual crops under nearly bare soil conditions (Eq. (76) in Allen et al., 1998). It can be seen in Fig. 4 that the maximum value of $f_{\mathrm{c}}$ varies from method to method and from field to field. For Local-Calibration method for example, it was equal to $0.82,0.72$ and 0.94 for fields 1,2 and 3, respectively. This is could be explained by the differences in agricultural practices of each field (sowing date, irrigation water and fertilization).

\section{Application of the FAO-56 "dual" crop coefficient model without calibration: No- Calibration method}

We simulate the time course of AET using the FAO-56 "dual" crop coefficient approach over winter wheat using

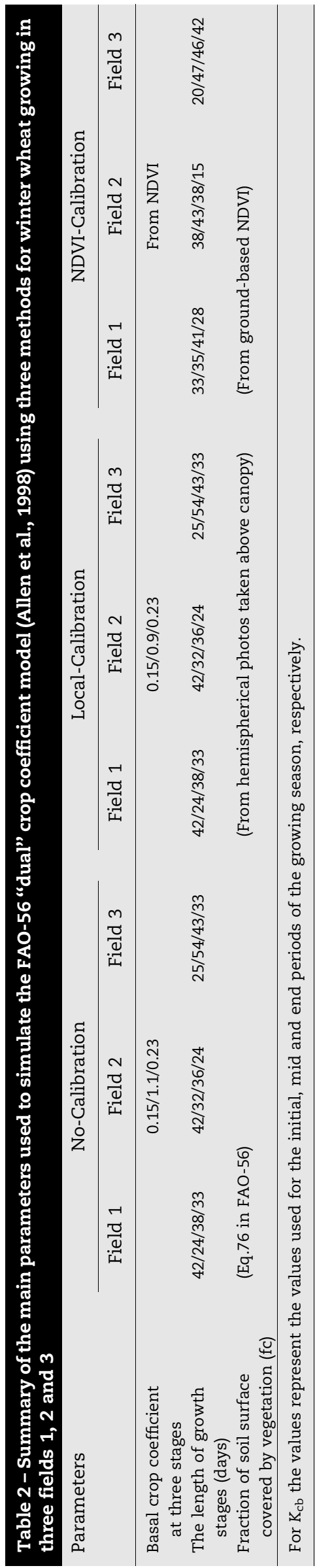



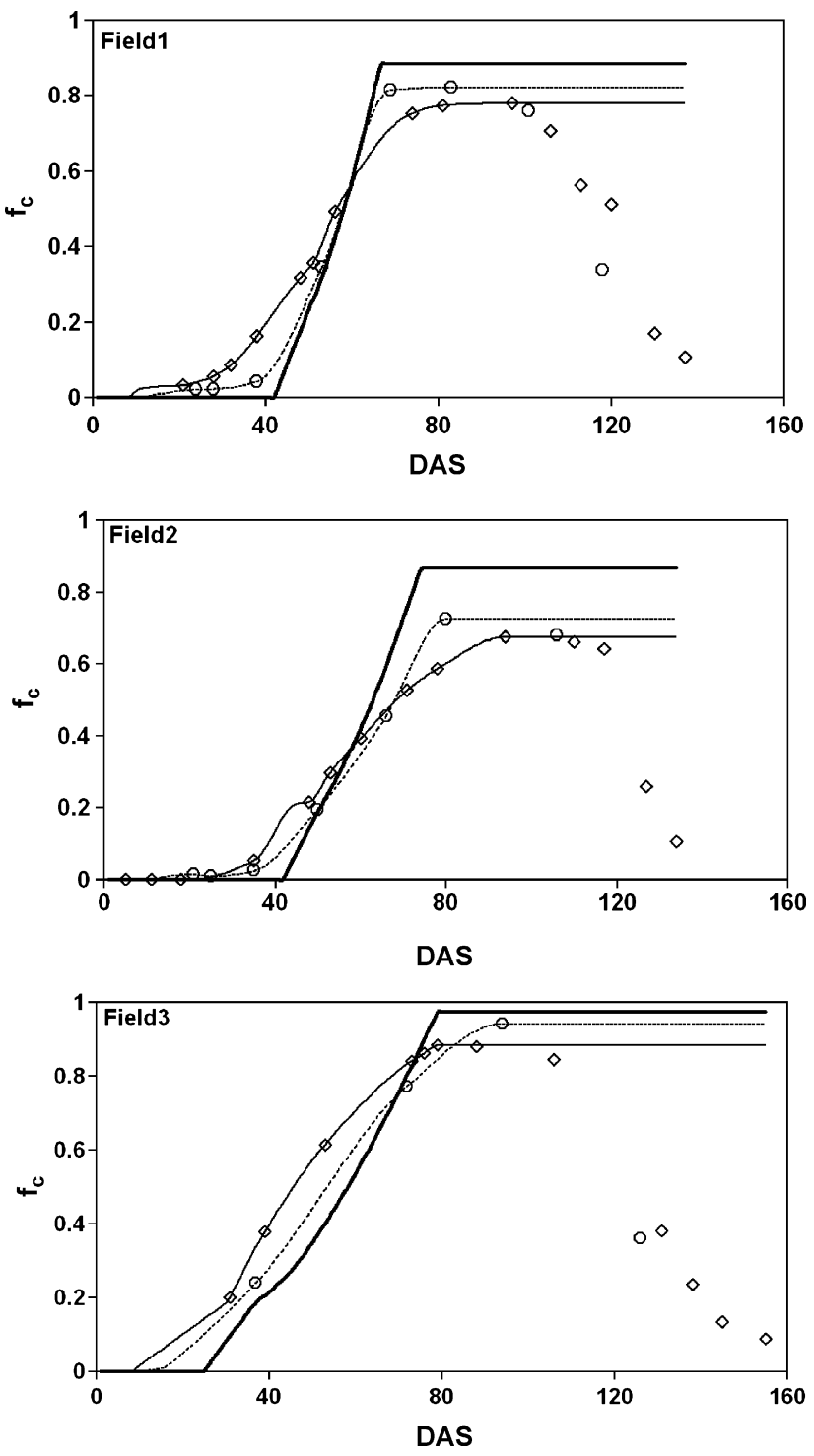

Fig. 4 - Daily interpolated $f_{c}$ from No-Calibration (bold solid lines), Local-Calibration (dotted lines) and NDVI-Calibration (solid lines) methods for three fields of study: fields 1, 2 and 3. Measured green cover (circles) by hemispheric photograph and derived green cover (lozenge) from measured NDVI were plotted. Note that as soon as $f_{c}$ reached their maximum, it takes equal this maximum value and remains constant.

the parameters given in the FAO-56 tables. Table 2 provides the parameters used to simulate the FAO-56 "dual" crop coefficient approach with No-Calibration method over three fields of study. The simulation has been performed from January 11th (DAS 1) through May 27th 2003 (DAS 137) for field 1, from January 14th (DAS 1) through May 27th 2003 (DAS 134) for field 2 and from December 17th (DAS 1) through May 20th 2003 (DAS 155) for field 3.

Comparison between observed and simulated AET using the No-Calibration method for three fields of study is presented in Fig. 6 (figures in left). According to this
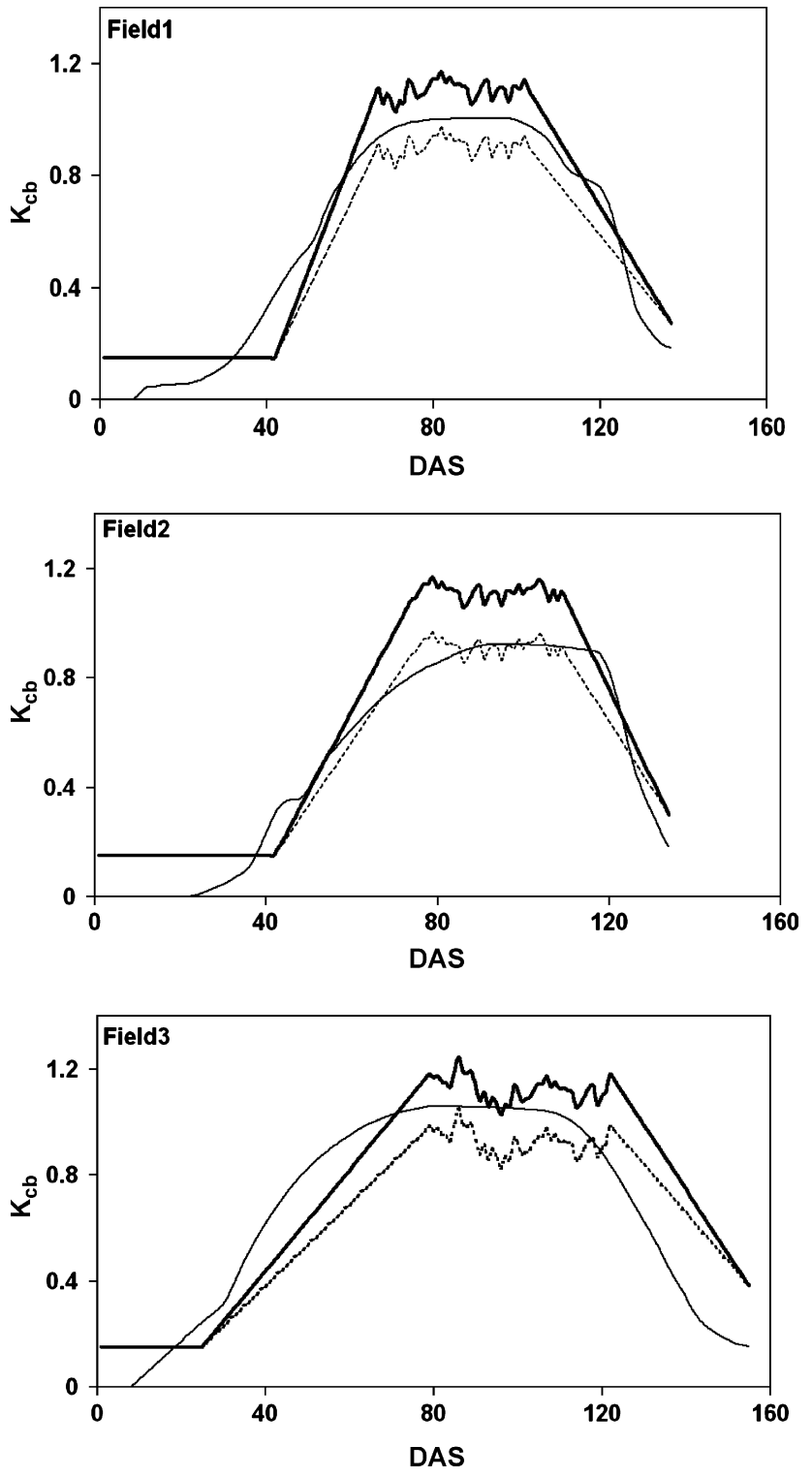

Fig. 5 - Daily time course of $K_{\mathrm{cb}}$ for No-Calibration (bold solid lines), Local-Calibration (dotted lines) and NDVI-Calibration (solid lines) methods for three fields of study: fields 1,2 and 3.

figure, the FAO-56 "dual" crop coefficient approach gives acceptable results over field 1 , however the performance of the model is poor over fields 2 and 3 (see statistical analysis in Table 3, equations used are provided in Appendix A). There are several reasons to explain such poor behaviour.

- The model tends to overestimates AET value at the midseason stage. The value of $K_{\mathrm{cb}}$ at this stage may not appropriate.

- The eddy correlation system measures the evapotranspiration over a relatively large area (wet and dry) whereas the model simulates it locally. This is due to the heterogeneous irrigation (flooding technique) and the partially 


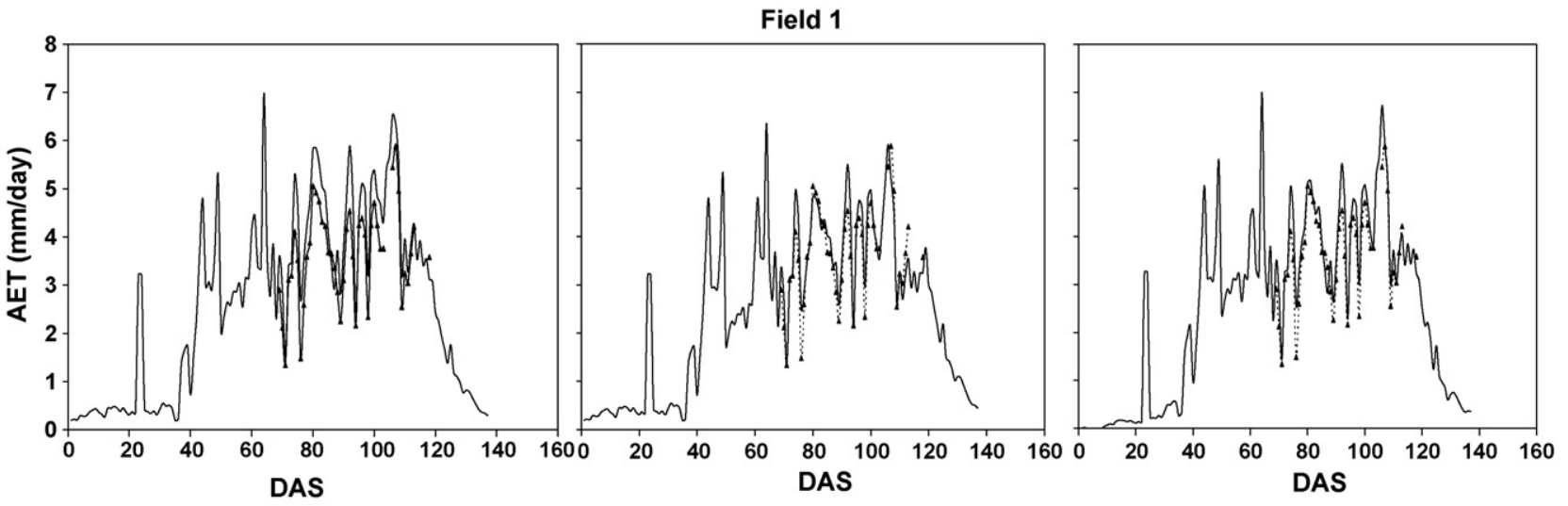

Field 2
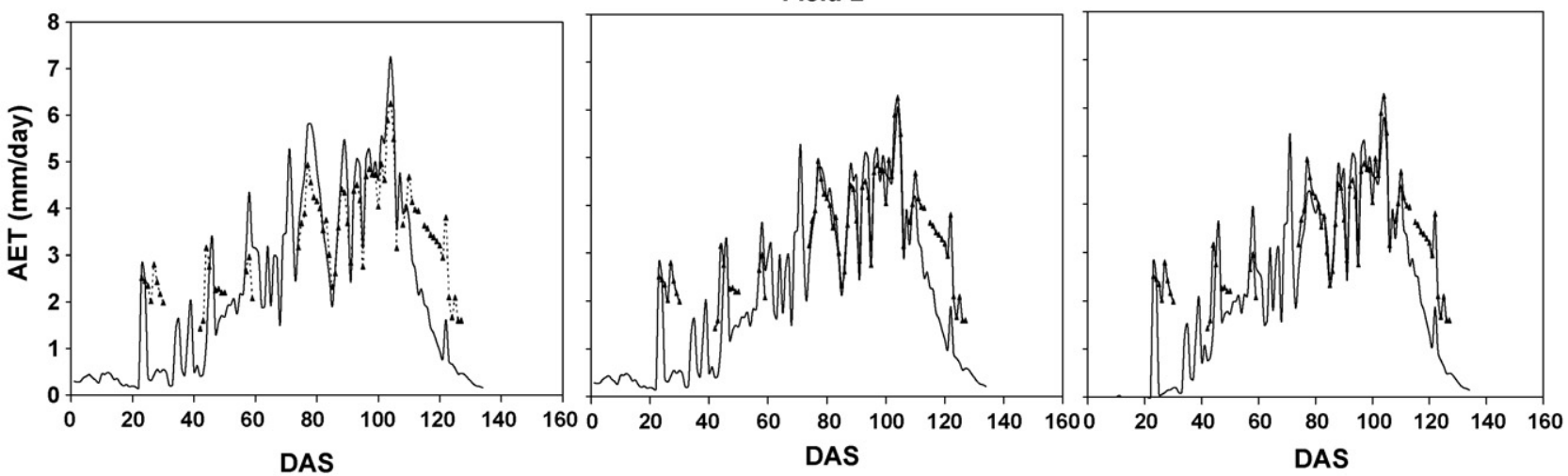

Field 3
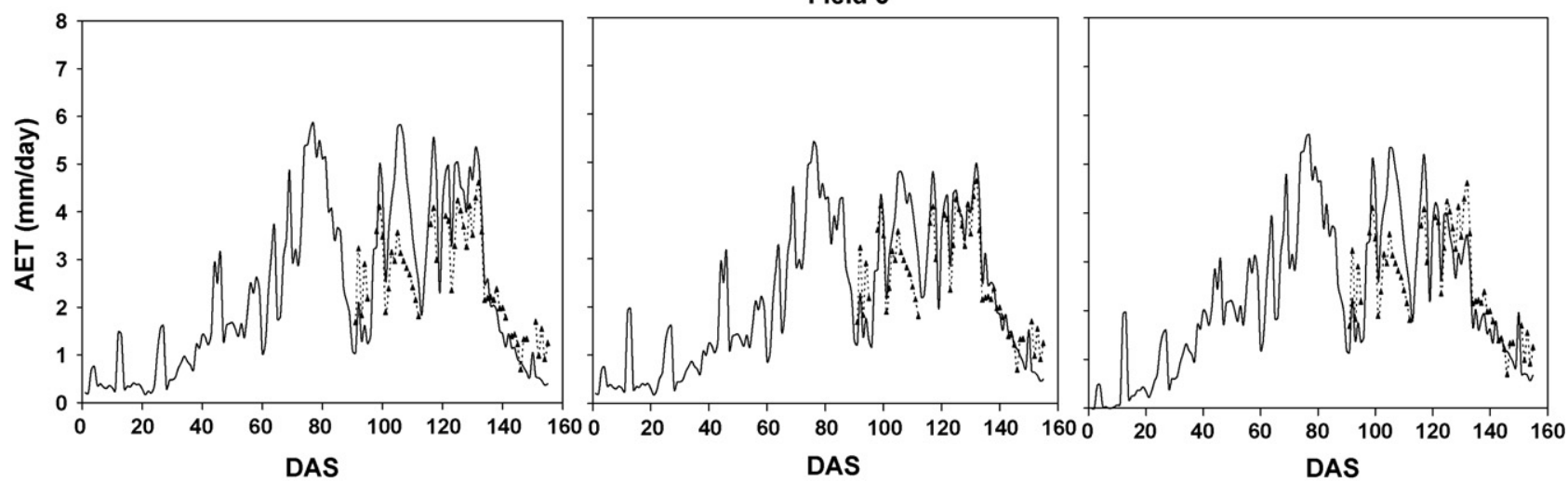

Fig. 6 - Comparison of observed daily actual evapotranspiration AET (triangles on dotted line) and estimated ET (solid line) by three methods: No-Calibration (left), Local-Calibration (middle) and NDVI-Calibration (right) methods for three fields of study: field 1 (top figures), field 2 (middle figures) and field 3 (bottom figures).

wetted area can be present in the flux source area measured by eddy covariance, depending on wind speed and direction. This can be clearly seen between DAS 25 and DAS 30 in Fig. 6 for field 2.

- The model might not simulate correctly the water stress coefficient $K_{\mathrm{s}}$, this is clear after DAS 110 for field 2 and in between DAS 105 and DAS 111 for field 3 when simulated AET decreases rapidly.

Based on these findings, attention should be paid to the possible effect on simulation of AET by applying the FAO-56 "dual" crop coefficient approach without calibration. Although this approach (Allen et al., 1998) is often preferred to calculate crop water requirements and for irrigation scheduling due to its simplicity and thus its applicability for operational purposes, it tends to overestimates AET at midseason stage by about $16 \%, 10 \%$ and $17 \%$ for fields 1,2 and 3 , respectively. This overestimation is much higher than that reported in Allen (1999) when he applied the FAO-56 dual procedure to a 200,000 ha irrigation project in California (overestimation of $6 \%$ ).

It is therefore not cautious to apply the FAO-56 dual approach without local calibration, this may lead to significant uncertainties in estimating water need and consumption and thus crop yield. 
Table 3 - Statistics analysis of actual evapotranspiration (AET) simulated by the FAO-56 "dual" crop coefficient with three methods (No-Calibration, Local-Calibration and NDVI-Calibration) of winter wheat growing in three fields of study: 1, 2 and 3

\begin{tabular}{|c|c|c|c|}
\hline Statistical parameters & Field 1 & Field 2 & Field 3 \\
\hline \multicolumn{4}{|l|}{ No-Calibration } \\
\hline$n$ & 45 & 71 & 56 \\
\hline Slope & 1.05 & 1.47 & 1.53 \\
\hline Y-intercept & 0.42 & -1.98 & -0.99 \\
\hline$R^{2}$ & 0.87 & 0.74 & 0.78 \\
\hline RMSE & 0.74 & 1.15 & 1.05 \\
\hline MBE & 0.61 & -0.38 & 0.40 \\
\hline E & 0.44 & -0.11 & -0.09 \\
\hline \multicolumn{4}{|l|}{ Local-Calibration } \\
\hline$n$ & 45 & 71 & 56 \\
\hline Slope & 0.86 & 1.11 & 1.18 \\
\hline Y-intercept & 0.64 & -0.73 & -0.25 \\
\hline$R^{2}$ & 0.82 & 0.65 & 0.76 \\
\hline RMSE & 0.45 & 0.99 & 0.75 \\
\hline MBE & 0.16 & -0.53 & 0.24 \\
\hline$E$ & 0.79 & 0.17 & 0.44 \\
\hline \multicolumn{4}{|l|}{ NDVI-Calibration } \\
\hline$n$ & 45 & 71 & 56 \\
\hline Slope & 0.96 & 1.25 & 1.11 \\
\hline Y-intercept & 0.47 & -1.37 & -0.20 \\
\hline$R^{2}$ & 0.56 & 0.73 & 0.64 \\
\hline RMSE & 0.51 & 1.01 & 0.86 \\
\hline MBE & 0.33 & -0.52 & 0.09 \\
\hline E & 0.73 & 0.15 & 0.27 \\
\hline
\end{tabular}

$n$ : number of observations; Y-intercept: the intercept $\left(\mathrm{mm} \mathrm{day}^{-1}\right)$; $R^{2}$ : the correlation coefficient (no units); RMSE: root mean square error ( $m m$ day $\left.{ }^{-1}\right)$; MBE: mean bias error $\left(\mathrm{mm}\right.$ day $\left.^{-1}\right)$; $E$ : efficiency (no units).

\section{Calibration and validation of the FAO-56 "dual" crop coefficient model: Local-Calibration method}

The FAO-56 "dual" crop coefficient model was first calibrated over field 1 and then validated over fields 2 and 3. In addition to soil parameters, some plant parameters were also calibrated. The main parameter is the value of $K_{\text {cbmid }}$ at the mid-season stage. The calibration was performed manually based on the combination of parameters that provide the best efficiency between measured and simulated AET. The results presented in Table 2 show that the values of the calibrated parameters are within the range given in Allen et al. (1998). The $K_{\mathrm{cb}}$ value at the mid-season stage was found to be considerably less than the FAO-56 recommended $K_{\mathrm{cb}}$ value. The value of $K_{\mathrm{cbmid}}$ is only 0.90 while that given in FAO-56 manual is 1.1 . This reduction in $K_{\text {cbmid }}$ value suggests that the crop is not growing in optimal conditions. This is due to stresses induced by shortage of water and nitrogen which affect the growth of wheat (Bandyopadhyay and Mallick, 2003).

The comparison between measured and estimated AET by the "dual" crop coefficient after the calibration procedure shows good agreements between observed and simulated
AET values (Fig. 6) (figure in the middle for field 1). The root mean square error (RMSE) and the efficiency $(E)$ between measured and simulated AET values were respectively about $0.45 \mathrm{~mm}$ day $^{-1}$ and 0.79 after calibration while the corresponding statistics without calibration were $0.74 \mathrm{~mm} \mathrm{day}^{-1}$ and 0.44. Additional statistical results are presented in Table 3.

\subsection{Model validation}

In this section, we present the performance of the simulations obtained after calibration of the FAO-56 "dual" crop coefficient model on field evapotranspiration measurements over fields 2 and 3.

Fig. 6 (figures in the middle for fields 2 and 3) illustrate, respectively, the time course of measured and simulate AET by the FAO-56 "dual" model for fields 2 and 3, respectively. Obviously, actual evapotranspiration appears better reproduced for both fields after the Local-Calibration method. The efficiency ( $E$ ) between measured and simulated AET values for fields 2 and 3 were respectively about 0.17 and 0.44 after calibration while they were -0.11 and -0.09 before. The additional statistical results presented in Table 3 confirm this clear improvement in the simulation of AET. However, some discrepancies between measured and simulated AET can still be seen. Particularly, after 2 days of the first irrigation in field 2, the model gives the low AET values while those provided by the eddy correlation system were relatively larger (DAS 25 to DAS 30). This behaviour might be explained by the heterogeneity of the soil moisture due the irrigation method (flooding irrigation). In fact, the eddy correlation system which capture the flux emanating from a larger area (footprint) than that simulated by the model. Another factor that may partly explain some of the difference between measured and simulated AET values is the crop stress. This is can be seen after DAS 111 for field 2 and between DAS 104 and DAS 112 for field 3 (Fig. 6). This could be explained by the misrepresentation of the rooting depth which directly influence the ability of the plant to extract water. In fact, the rooting depth $Z_{r}$ was assumed to vary between a minimum value (maintained during the initial crop growth stage at $0.1 \mathrm{~m}$ ) and a maximum value (reached at the beginning of the mid-season stage). The root density of wheat is generally larger near the soil surface and declines with increase of depth (SCS, 1991) and the extraction of water occurs in the zone of the largest root concentration. At the end of growing season, the model underestimates AET. A possible explanation here could be the contribution of deep soil layer in the evaporate water through capillarity rising which not taken into account by the model. To successfully take into account the physical process involved in the exchange processes one could use models like SWIM (soil water infiltration and movement, Ross, 1990) or SiSPAT (simple soil plant atmosphere, Braud et al., 1995). However, these models require many more parameters than FAO-56, and therefore difficult to operationally in the large area. Nevertheless, this type of models can be useful to improve some the parameterisation used in FAO-56 but this is out of the scope of the present study. 
Table 4 - Simulated cumulative soil evaporation (SE), crop transpiration (CT), and actual evapotranspiration (AET) for each field (1, 2, and 3) using three methods based on the FAO-56 "dual" crop coefficient model

\begin{tabular}{|c|c|c|c|c|c|c|c|c|c|}
\hline & \multicolumn{3}{|c|}{ No-Calibration } & \multicolumn{3}{|c|}{ Local-Calibration } & \multicolumn{3}{|c|}{ NDVI-Calibration } \\
\hline & Field 1 & Field 2 & Field 3 & Field 1 & Field 2 & Field 3 & Field 1 & Field 2 & Field 3 \\
\hline $\mathrm{SE}(\mathrm{mm})$ & 45.39 & 25.02 & 23.46 & 56.51 & 38.05 & 34.15 & 49.13 & 39.20 & 25.99 \\
\hline $\mathrm{CT}(\mathrm{mm})$ & 307.79 & 269.75 & 336.87 & 274.26 & 242.22 & 307.14 & 289.17 & 229.45 & 324.57 \\
\hline AET (mm) & 353.18 & 294.77 & 360.34 & 330.77 & 280.28 & 341.29 & 338.30 & 268.66 & 350.56 \\
\hline
\end{tabular}

\section{Integration of remote sensing in the FAO-56 "dual" crop coefficient model to crop water requirements: "NDVI-Calibration" method}

In order to avoid the necessity of calibrating FAO-56 method over each study area, which greatly limits its operational utilization, we investigated how remote sensing data can be used to derive some key parameters. To achieve this, relationships between NDVI and $K_{\mathrm{cb}}$ and NDVI and $f_{\mathrm{c}}$ were incorporated within the FAO-56 "dual" crop coefficient model, with linear established relationships between $K_{\mathrm{cb}}$ and NDVI and $f_{\mathrm{c}}$ and NDVI (see Eqs. (4) and (5)). The use of $f_{\mathrm{c}}$ and $K_{\mathrm{cb}}$ by NDVI-Calibration method were plotted in Figs. 4 and 5 , respectively. During the initial stage, the values of $f_{\mathrm{c}}$ and $K_{\mathrm{cb}}$ were 0 for all fields, this is because the values of NDVI at this stage were assumed to be equal to the $\mathrm{NDVI}_{\text {min }}$ (see Eqs. (8) and (9)). It can be seen in Fig. 4 that the maximum value of $f_{c}$ varies between fields. It was $0.78,0.67$ and 0.88 for fields 1,2 and 3, respectively. Similarly, the maximum value of $K_{\mathrm{cb}}$ also varies from field to field; being 1.01, 0.92 and 1.05 for fields 1, 2 and 3, respectively (Fig. 5). This difference reflects the status, the vigour and the amount of vegetation in each field.

Comparison between observed and simulated AET by NDVI-Calibration method for three fields of study is presented in Fig. 6 (figures in right). According to these figures, the actual evapotranspiration appears well reproduced by this method over field 1. The (RMSE) and the (E) between measured and simulated AET values were respectively about $0.51 \mathrm{~mm} \mathrm{day}^{-1}$ and 0.73 . For fields 2 and 3, AET was not very well reproduced by the model (see statistical parameters in Table 3). At the initial stage, the model underestimates evapotranspiration over field 2 from DAS 25 to DAS 30 in Fig. 6 because the values of $K_{\mathrm{cb}}$ was 0 and soil evaporation was poorly simulated. Based on the results obtained in the above section (Local-Calibration method), this poor performance can be explained by the error associated with the linear relationships NDVI- $f_{\mathrm{c}}$ and NDVI-K $K_{\mathrm{cb}}$ over fields 2 and 3.

\section{Comparison between three methods in terms of estimates of evaporation and transpiration}

In addition to the fact that the "dual" crop coefficient approach allowed to incorporate remote sensing of $K_{\mathrm{cb}}$ into the method which is not possible with a "single" crop coefficient approach, the "dual" crop coefficient approach allowed to separately estimate the contributions of the soil and of the vegetation to AET. In this paragraph, we will compare the simulated AET using three methods based on the FAO-56 "dual" crop coefficient model and to explain their differences in terms of the way that components evapotransipration are computed.

Table 4 shows simulated cumulative AET and its components (soil evaporation and crop transpiration) for each field
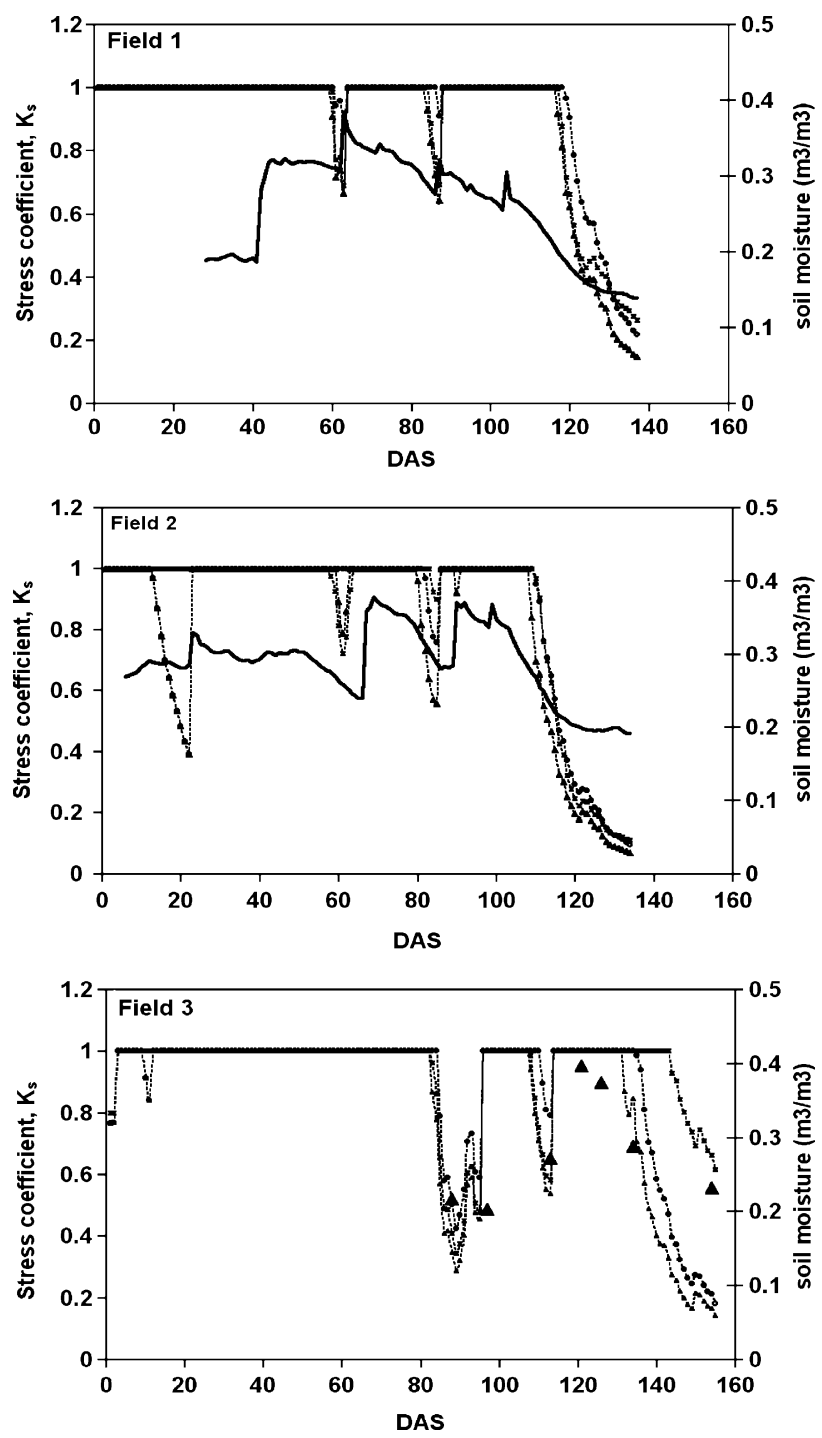

Fig. 7 - Estimated daily soil water stress coefficient $K_{s}$ by FAO-56 "dual" crop coefficient model used three different methods - No-Calibration, triangles on dotted line; LocalCalibration, circles on dotted line and NDVI-Calibration, stars on dotted line - of winter wheat growing in three fields of study: fields 1, 2 and 3. The measured soil moisture by (TDR) at the root zone (solid line) is also shown in the same figure. Note that for field 3 , the soil moisture at the root zone (big triangles) was measured with gravimetric technique. 
(1, 2, and 3) using three methods based on the FAO-56 "dual" crop coefficient model. As it can be seen in this table, the difference in the values of estimated AET by different methods is a consequence of the difference between the simulated values of soil evaporation and plant transpiration. Regarding the soil evaporation, it was different from method to method and from field to field (Table 4). The difference in soil evaporation between different methods is due to the fraction of soil surface covered by vegetation $f_{c}$ and the basal crop coefficient $K_{\mathrm{cb}}$ according to Eq. (71) in Allen et al. (1998). The variability of soil evaporation between three fields is also due to the irrigation management.

Concerning plant transpiration, it was also different between the three fields, as a result of the differences of length of growing season and on irrigation management. The simulated cumulative transpiration when using LocalCalibration method is about $30 \mathrm{~mm}$ lower than that estimated by No-Calibration one. As expected, the transpiration differences regarding both methods were due to the values of basal crop coefficients at mid-season, which were reduced from 1.1 to 0.9. Again, the estimated daily values of $K_{\mathrm{cb}}$ based on NDVI measurements (NDVI-Calibration) were set to 0 at the initial stage. This leads to a difference in transpiration estimates according the method used. Another factor that affects plant transpiration is the soil water stress coefficient $K_{\mathrm{s}}$. Fig. 7 shows the estimated daily soil water stress coefficient $K_{\mathrm{s}}$ by FAO-56 "dual" crop coefficient used three methods for each field of study. The measured soil moisture at the root zone is also shown in the same figure. The estimated $K_{\mathrm{s}}$ varies from field to field and from method to method. The soil water stress coefficient, $K_{\mathrm{s}}$, changes from 0 to 1 according to Eq. (3) and it depends on the soil water depletion linked to water supply (rainfall or irrigation). The diminution of $K_{\mathrm{s}}$ may be attributed to the increase in water depletion at the root zone through a removal of water by transpiration and percolation losses that induced stress condition and diminution of soil moisture at the root zone.

It can be seen that the estimated soil water stress coefficient $K_{\mathrm{S}}$ is not identical for the three methods although the water supply is similar. This difference is a consequence of the soil depletion factor $p$ that depends on $\mathrm{ET}_{\mathrm{c}}$ (Eq. (4)) which depends on basal crop coefficient. The adjustment of soil depletion factor $p$ with high or low values of $\mathrm{ET}_{\mathrm{c}}$ provides an underestimation or overestimation of water stress coefficient $\mathrm{K}_{\mathrm{s}}$. The overestimation of $\mathrm{K}_{\mathrm{s}}$ estimated by NDVI-Calibration method can be clearly seen after DAS 135 for field 3 in Fig. 7 when the values of $K_{\mathrm{s}}$ remains high.

\section{Conclusions}

The main objective of this study is to test three methods for estimating seasonal AET over winter wheat under different irrigation treatments in semi-arid region Tensift AlHaouz, Marrakech province, south Morocco. All of those methods are based on the FAO-56 "dual" crop coefficient approach, but they differ in the method used to estimate $K_{\mathrm{cb}}$ and $f_{\mathrm{c}}$. The first approach (No-Calibration) uses $K_{\mathrm{cb}}$ given in tables FAO-56, and $f_{c}$ is calculated from $K_{c b}$. The second method (Local-Calibration) uses a locally derived $K_{\mathrm{cb}}$ and $f_{\mathrm{c}}$ based on field measurements, with the last approach (NDVI-Calibration) uses a ground based remotely-sensed vegetation indices to estimate $K_{\mathrm{cb}}$ and $f_{\mathrm{c}}$.

The results showed that the FAO-56 "dual" crop coefficient approach was unable to accurately estimate crop evapotranspiration using parameters values provided by FAO-56. An application of this model required some local adaptation (local calibration). For instance, the basal crop coefficient at the mid-season was found to be 0.9 which is considerably lower than the value of 1.1 recommended in FAO-56. This reduction was about $18 \%$ which indicates that the wheat was not growing in optimal condition.

Consequently, the performances of AET simulations were very different according to the used methods. It was shown that the locally derived $K_{\mathrm{cb}}$ and $f_{\mathrm{c}}$ based on field measurements gives good results, but some differences between measured and estimated AET appear when the stress and soil evaporation occurred. The differences in AET estimates are explained by two-fold: (1) the difference in soil evaporation due to the fraction of soil surface covered by vegetation $f_{c}$ and the basal crop coefficient, and (2) the difference in plant transpiration due to basal crop coefficient $K_{\mathrm{cb}}$ and soil stress coefficient $K_{\mathrm{s}}$.

The similarity between seasonal patterns of NDVI and $K_{\mathrm{cb}}$ showed potential for establishing relationships between NDVI and $K_{\mathrm{cb}}$ and $f_{\mathrm{c}}$, relationships which have been incorporated into the FAO-56 "dual" crop coefficient model and have yielded highly satisfactory results, especially when the soil evaporation is negligible. Therefore, the $K_{\mathrm{cb}}-\mathrm{NDVI}$ relationship employed in the FAO-56 "dual" crop coefficient model provide a great potential for estimating at an operational basis crop water requirements and consumption at a regional scale.

Having compared estimated AET by different methods and measured AET by eddy correlation system, we conclude that the Local-Calibration method gives the estimation of AET. To reduce errors when using the FAO-56 "dual" crop coefficient model, accurate estimates of $K_{\mathrm{cb}}$ and $f_{\mathrm{c}}$ are necessary.

Finally, it should be noted that all the observations that have been used to calibrate and validate the FAO-56 dual crop coefficient approach are derived from three fields datasets acquired on irrigated wheat crops with a particular environment (soil and climate). In order to deliver detailed spatial and temporal information regarding soil and crop response (evapotranspiration) to varied management practices and dynamic environmental conditions, and to avoid the timeconsuming process of calibrating the FAO-56 method over each field, the use of remote sensing data would be necessary.

\section{Acknowledgements}

This study was supported by the European Union 5th Framework through an INCO-MED Programme: IRRIMED ('Improved management tools for water-limited irrigation: combining ground and satellite information through models'), see http:// www.irrimed.org/. The authors would like to sincerely thank to Sud-Med technical partners especially ORMVAH ('Office Regional de Mise en Valeur Agricole du Haouz', Marrakech, Morocco) for its technical help as well as Drs. Boulet and Olioso for their help during the course of this study. 


\section{Appendix A. Statistical analysis}

Four statistics were used for analysing the data: (1) the mean bias error (MBE), which indicates the average deviation of the predicted values from the measured values; (2) the root mean square error (RMSE), which measures the variation of predicted values around observed values; (3) the efficiency $(E)$, which characterizes the performances of the model simulation (the perfect model should have the efficiency close to 1, Zacharias et al., 1996); (4) the correlation coefficient $\left(R^{2}\right)$, which shows the degree to which two variables are linearly related.

$$
\begin{aligned}
& \text { MBE }=y_{\text {mod }}-y_{\text {obs }} \\
& E=1-\frac{\sum_{i=1}^{n}\left(y_{\text {imod }}-y_{i o b s}\right)^{2}}{\sum_{i=1}^{n}\left(y_{i o b s}-y_{\text {obs }}\right)^{2}} \\
& \text { RMSE }=\sqrt{\frac{1}{n} \sum_{i=1}^{n}\left(y_{i \text { mod }}-y_{\text {iobs }}\right)^{2}}
\end{aligned}
$$

where $y_{\text {mod }}$ and $y_{\text {obs }}$ are the averages of model and observations, respectively, $n$ the number of available observations, and $y_{i \text { mod }}$ and $y_{i \text { obs }}$ are daily values of modelled and observed variables, respectively.

\section{REFERE N C ES}

Allen, R.G., Smith, M., Perrier, A., Pereira, L.S., 1994a. An update for the definition of reference evapotranspiration. ICID Bull. 43 (2), 1-34.

Allen, R.G., Smith, M., Pereira, L.S., Perrier, A., 1994b. An update for the calculation of reference evapotranspiration. ICID Bull. 43 (2), 35-92.

Allen, R.G., Pereira, L.S., Raes, D., Smith, M., 1998. Crop Evapotranspiration-Guidelines for Computing Crop Water Requirements, Irrigation and Drain, Paper No. 56. FAO, Rome, Italy, 300 pp.

Allen, R.G., 1999. Concept paper-accuracy of predictions of project-wide evapotranspiration using crop coefficients and reference evapotranspiration in a large irrigation project. In: Proceedings of the United States Committee on Irrigation and Drainage Conference on "Benchmarking Irrigation System Performance Using Water Measurement and Water Balances, San Luis Obispo, CA, 10-13 March.

Allen, R.G., 2000. Using the FAO-56 dual crop coefficient method over an irrigated region as part of an evapotranspiration intercomparison study. J. Hydrol. 229, 27-41.

Allen, R.G., Tasumi, M., 2003. Application of SEBAL for western US water rights regulation and planning. Proceedings of the International Workshop Use of Remote Sensing of Crop Evapotranspiration for large Regions.

Bandyopadhyay, P.K., Mallick, S., 2003. Actual evapotranspiration and crop coefficients of wheat (Triticum aestivum) under varying moisture levels of humid tropical canal command area. Agric. Water Manage. 59, 33-47.

Bastiaanssen, W.G.M., Molden, D.J., Makin, I.W., 2000. Remote sensing for irrigated agriculture: examples from research and possible applications. Agric. Water Manage. 46 (2), 137-155.

Bausch, W.C., Neale, C.M.U., 1987. Crop coefficients derived from reflected canopy radiation: a concept. Trans. ASAE 30 (3), 703-709.
Bausch, W.C., Neale, C.M.U., 1989. Spectral inputs improve corn crop coefficients and irrigation scheduling. Trans. ASAE 32 (6), 1901-1908.

Bausch, W.C., 1993. Soil background effects on reflectancebased crop coefficients for corn. Rem. Sens. Environ. 46, 213-222.

Bausch, W.C., 1995. Remote sensing of crop coefficients for improving the irrigation scheduling of corn. Agric. Water Manage. 27, 55-68.

Chehbouni, A., Escadafal, R., Dedieu, G., Errouane, S., Boulet, G., Duchemin, B., Mougenot, B., Simonneaux, V., Seghieri, J., Timouk, F., 2003. A multidisciplinary program for assessing the sustainability of water resources in semi-arid basin in Morocco. In: Proceedings of the SUDMED. EGS-AGU-EUG Joint Assembly, Nice France 6-11 April 2003.

Choudhury, B.J., Ahmed, N.U., Idso, S.B., Reginato, R.J., Daughtry, C.S.T., 1994. Relations between evaporation coefficients and vegetation indices studies by model simulations. Rem. Sens. Environ. 50, 1-17.

Doorenbos, J., Pruitt, W.O., 1977. Crop water requirements. Food and Agriculture Organization of the United Nations. FAO Irrigation and Drainage Paper No. 24, Rome, 1977, 144 pp. (revised).

Doorenbos, J., Kassam, A.H., 1979. Yield response to water. Food and Agriculture Organization of the United Nations. FAO Irrigation and Drainage Paper No. 33, Rome, 1986, 193 pp. (revised).

Duchemin, B., Hadria, R., Er-Raki, S., Boulet, G., Maisongrande, P., Chehbouni, A., Escadafal, R., Ezzahar, J., Hoedjes, J., Karroui, H., Khabba, S., Mougenot, B., Olioso, A., Rodriguez, J.-C., Simonneaux, V., 2006. Monitoring wheat phenology and irrigation in Central Morocco: on the use of relationship between evapotranspiration, crops coefficients, leaf area index and remotely-sensed vegetation indices. Agric. Water Manage. 79, 1-27.

Eitzinger, J., Marinkovic, D., Hösch, J., 2002. Sensitivity of different evapotranspiration calculation methods in different crop-weather models. In: Rizzoli, A.E., Jakeman, A.J. (Eds.), Proceedings of the First Biennial Meeting of the International Environmental Modelling and Software Society (IEMSS) on Integrated Assessment and Decision Support, vol. 2, Lugano, Switzerland, 24-27 June, pp. 395-400.

Englund, S.R., O’Brien, J.J., Clark, D.B., 2000. Evaluation of digital and film hemispherical photography for predicting understorey light in a Bornean tropical rain forest. Agric. For. Meteoric. 97, 129-139.

Er-Raki, S., Chehbouni, G., Guemouria, N., Ezzahar, J., Duchemin, B., Hadria, R., Boulet, G., Lakhal, A., Chehbouni, A., Rodriguez, J.C., 2004. The feasibility of using remotely sensed measures of vegetation index to estimate crop water requirement of winter wheat in semi-arid region (Marrakech, Morocco). In: Proceedings of the International Conference on Integrated Water Resources Research and Development in Southeastern Morocco, Ouarzazate, Morocco, 01-02 April.

Evett, S.R., Howell, T.A., Schneider, A.D., Tolk, J.A., 1995. Crop coefficient based evapotranspiration estimates compared with mechanistic model results. In: Espey, W.H., Combs, P.G. (Eds.), Proceedings of the First International Conference on Water Resources Engineering, vol. 2, San Antonio, Texas, USA, August 14-18.

Gutman, G.G., 1999. On the use of long-term global data of land reflectances and vegetation indices derived from the advanced very high resolution radiometer. J. Geophys. Res. 104, 6241-6255.

Hadria, R., Khabba, S., Lahrouni, A., Duchemin, B., Chehbouni, A.G., Ouzine, L., Carriou, J., 2005. Calibration and validation of the STICS crop model for managing wheat irrigation in 
the semi-arid Marrakech/Al Haouz Plain. Arab. J. Sci. Eng., Special Issue "Potential Water Challenges and Solutions in the New Millennium in Arid Regions" 30 (2B).

Hale, S.E., Edwards, C., 2002. Comparison of film and digital hemispherical photography across a wide range of canopy densities. Agric. For. Meteorol. 112, 51-56.

Heilman, J.L., Heilman, W.E., Moore, D.G., 1982. Evaluating the crop coefficient using spectrales reflectance. Agron. J. 74, 967-971.

Huete, A.R., 1988. A Soil-adjusted vegetation index (SAVI). Rem. Sens. Environ. 25, 295-309.

Hunsaker, D.J., Pinter Jr., P.J., Barnes, E.M., Kimball, B.A., 2003. Estimating cotton evapotranspiration crop coefficients with a multispectral vegetation index. Irrig. Sci. 22, 95-104.

Jackson, R.D., Idso, S.B., Reginato, R.J., Pinter Jr., P.J., 1980. Remotely sensed crop temperatures and reflectances as inputs to irrigation scheduling. In: Proceedings of the Special Conference on Irrigation and Drainage, Boise, Idaho. ASCE, New York, 23-25 July, pp. 390-397.

Jackson, R.D., Huete, A.R., 1992. Interpreting vegetation indices. Prev. Vet. Med. 11, 185-200.

Jensen, M.E., Burman, R.D., Allen, R.G., 1990. Evapotranspiration and irrigation water requirement. ASCE Manuals and Reports on Engineering Practice No. 70, p. 332.

Jonckheere, I., Fleck, S., Nackaerts, K., Muys, B., Coppin, P., Weiss, M., Baret, F., 2003. Review of methods for in situ leaf area index determination. Part I. Theories, sensors and hemispherical photography. Agric. For. Meteorol. 94, 243-257.

Karrou, M., 2003. Conduite du blé au Maroc. Institut National de la recherche agronomique (INRA), Rabat, pp. 1-57.

Kite, G.W., Droogers, P., 2000. Comparing evapotranspiration estimates from satellites, hydrological models and field data. J. Hydrol. 209, 3-18.

Moran, M.S., Mass, S.J., Pinter Jr., P.J., 1995. Combining remote sensing and modelling for estimating surface evaporation and biomass production. Rem. Sens. Rev. 12, 335-353.

Neale, C.M.U., Bausch, W.C., Heerman, D.F., 1989. Development of reflectance-based crop coefficients for corn. Trans. ASAE 32 (6), 1891-1899.

Pascon, P., 1977. Le Haouz de Marrakech. CURS/CNRS/1NAV, Rabat/Paris/Rabat, 693 p.
Pruitt, W.O., Fereres, E., Kaita, K., Snyder, R.L., 1987. Reference evapotranspiration $\left(\mathrm{ET}_{0}\right)$ for California. Agriculture and Experiment Station Bulletin 1922. University of California, 16 pp. and 12 maps.

Ross, P.J., 1990. 'SWIM-a simulation model for soil water infiltration and movement'. Reference Manual to SWIMv1', CSIRO Division of Soils, Australia.

Rouse J.W., Haas R.H., Schell J.A., Deering D.W., Harlan J.C., 1974. Monitoring the vernal advancement and retrogradation of natural vegetation. NASA/GSFC, Type III, Final report, Greenbelt, MD, pp. 1-371.

SCS, 1991. Soil-plant-water relationships. In: National Engineering Handbook, Section 15, Irrigation. Soil Conservation Service, US Department of Agriculture, Washington, USA, 56 pp. (Chapter 1).

Sibernagel, J., Moeur, M., 2001. Modeling canopy openness and understory gap patterns based on image analysis and mapped tree data. For. Ecol. Manage. 149, 217-233.

Smith, M., Allen, R.G., Monteith, J.L., Pereira, L.S., Perrier, A., Pruitt, W.O., 1991. Report on the Expert Consultation on Procedures for Revision of FAO Guidelines for Prediction of Crop Water Requirements. Land and Water Dev. Division, United Nations Food and Agriculture Service, Rome, Italy.

Snyder, R.L., Lanini, B.J., Shaw, D.A., Pruit, W.O., 1987. University of California. Division of Agricultural and Natural Resources Leaflet 21427, p. 12.

Van Gardingen, P.R., Jackson, G.E., Hernandez-Daumas, S., Russell, G., Sharp, L., 1999. Leaf area index estimates obtained for clumped canopies using hemispherical photography. Agric. For. Meteorol. 94, 243-257.

Van Genutchen, M.T., 1980. A closed-form equation for predicting the hydraulic conductivity of unsaturated soils. Soil Sci. Soc. Am. J. 44, 892-898.

Wosten, J.H.M., 1997. Pedotransfer functions to evaluate soil quality. In: Gregorich, E.G., Carter, M.R. (Eds.), Soil Quality for Crop Production and Ecosystem Health. Developements in Soil Science, vol. 25. Elsevier, Amsterdam, pp. 221-245.

Wosten, J.H.M., Lilly, A., Nemes, A., Le Bas, C., 1999. Development and use of a database of hydraulic properties of European soils. Geoderma 90, 169-218.

Zacharias, S., Heatwole, C.D., Coakley, C.W., 1996. Robust quantitative techniques for validating pesticide transport models. Trans. ASAE 39, 4754. 